\title{
LC-DAD-ESI-MS analysis of nitric oxide inhibitory fractions of tenggek burung (Melicope ptelefolia Champ. ex Benth)
}

\begin{abstract}
Solvent-solvent fractionation of the methanolic extract of the popular Malay traditional vegetable "tenggek burung" (Melicope ptelefolia), followed by nitric oxide inhibition assay on RAW 264.7 cells revealed that the most active components reside mainly in hexane and dichloromethane fractions. Online profiling of the nitric oxide (NO) inhibitive fractions of the tenggek burung using liquid chromatography coupled diode array detection and electrospray ion-trap tandem mass spectroscopy (LC-DAD-ESI-MSn), has identified seven constituents. The compounds were identified as kokusaginine (1), compound 2, [kokusagine, (2a) or 5methoxymaculine (2b)], 2,4,6-trihydroxy-3-prenylacetophenone (3), 2,4,6-trihydroxy-3geranylacetophenone (4), 2,4,6-trihydroxy-3-geranylgeranylacetophenone (5), 3-[4-O-(3,7dimethyl-2,6-octadienyl)phenyl]-2-propenoic acid (6) and 2,4,6-trihydroxy-3farnesylgeranylacetophenone (7). The identity of compounds 1,4 and 6 were unequivocally confirmed by isolation and spectroscopic evidences, other constituents are tentatively identified, based on their UV, MS, MSn and comparison with literature data. Kokusaginine (1) demonstrated in vitro activity on NO inhibition in murine peritoneal macrophages.
\end{abstract}

Keyword: LC-DAD-ESI-MSn; Nitric oxide inhibition; Melicope ptelefolia; Tenggek burung; Rutaceae; Acetophenone; Food analysis; Food composition 